\title{
The incidence of polyneuropthy and its relation with disease parameters in chronic obstructive pulmonary disease
}

\author{
Nalan Ogan ${ }^{1} \odot, \operatorname{Refah~Sayın}^{2} \odot$, Ayşe Baha$^{1} \odot$, Evrim Eylem Akpınar $^{1} \odot$, Meral Gülhan $^{3} \odot$ \\ ${ }^{1}$ Department of Chest Diseases, Ufuk University School of Medicine, Ankara, Turkey \\ ${ }^{2}$ Department of Neurology, Ufuk University School of Medicine, Ankara, Turkey \\ ${ }^{3}$ Department of Chest Diseases, Hitit University School of Medicine, Çorum, Turkey
}

DOI: 10.18621 /eurj.367066

\begin{abstract}
Objective: Chronic Obstructive Pulmonary Disease (COPD) is accompanied by several concomitant conditions due to its systemic effects. Hypoxia and oxidative stress associated with COPD are also believed to contribute to the disease course through the effects of several inflammatory mediators. Major causative agents causing of peripheral neuropathy are age, hypoxia, duration and severity of COPD, hypercapnia and smoking. The present study aimed to investigate the incidence of polyneuropathy and its relation with disease parameters in COPD patients.

Methods: Of a total number of 45 patients who had been followed up between January 1, 2015 and December 31, 2016 with a diagnosis of COPD at Ufuk University School of Medicine were enrolled retrospectively. All patients underwent electroneuromyography, arterial blood gas measurements and pulmonary function tests. Patients were divided as those with or without neuropathy, and factors contributing to the development of neuropathy were investigated based on clinical and laboratory findings.

Results: Eleven (24.4\%) patients were women and 34 (74.6\%) were men, and the mean age was 73.2 years. Mean $\mathrm{PaO}_{2}$ was $58.2 \mathrm{mmHg}$, $\mathrm{pCO}_{2}$ was $41.2 \mathrm{mmHg}$, and $\mathrm{FEV} 1$ was $45.3 \%$. Neuropathy was diagnosed in twenty (44.4\%) patients. Significant differences were found in $\mathrm{pO}_{2}, \mathrm{pCO}_{2}, \mathrm{SO}_{2}, \mathrm{mMRC}$, smoking status and number of exacerbations per year $(p<0.05)$.

Conclusions: Patients who experience frequent exacerbations and those with hypoxemia or hypercapnia as demonstrated should be taken into more careful clinical assessments with respect to polyneuropathy.

Keywords: chronic obstructive pulmonary disease, neuropathy, hypoxemia, hypercapnia, modified Medical Research Council
\end{abstract}

Received: December 16, 2017; Accepted: January 21, 2018; Published Online: April 2, 2018

$\sim$ hronic Obstructive Pulmonary Disease (COPD) is a common, preventable and treatable disease that is characterized by persistent respiratory symptoms and airflow limitation that is due to airway and/or alveolar abnormalities usually caused by significant exposure to noxious particles or gases [1].
COPD has several systemic effectsand the concurrent systemic inflammation was shown to be associated withdifferent concomitant diseases.Polyneuropathy is a clinical manifestation resulting from concomitant and common impairment of peripheral nerves due to the same causes and physiopathological processes.

Address for correspondence: Nalan Ogan, MD., Assistant Professor, Ufuk University School of Medicine, Department of Chest Diseases, Ankara, 
Causes of peripheral neuropathy include but not limited to diabetes mellitus, malignancy, Sjögrensyndrome, dysproteinemia, AIDS, Vitamin B12 deficiency, polyneuropathies due pyridoxine intoxication and hereditary or idiopathic sensorial polyneuropathies [2]. COPD is one of these causes (3). However, in patients who are diagnosed with peripheral neuropathy, COPD is usually ignored while the other potential causes are prioritized. This process that follows a chronic and deteriorating course eventually results in tissue hypoxemia and affects not only the lungs but the whole body. Previous studies investigated how the peripheral nerves and muscles are affected from this process. The objectives of the present study were to evaluate the neurophysiological changes in peripheral and central nervous systems in hypoxemic and/or hypercapnic COPD cases and to investigate the correlations of these changes with disease stage and the severity of dyspnea.

\section{METHODS}

Of a total number of 45 patients who had been followed up between January 1, 2015 and December 31, 2016 with a diagnosis of COPD at Ufuk University Faculty of Medicine were enrolled retrospectively. Complete blood count, biochemistry, Vitamin $\mathrm{B}_{12}$, folic acid and thyroid function test (TFT) results of all patients were evaluated. Patients with a history of cancer that might have caused peripheral neuropathy and those with a diagnosis of diabetes mellitus, vitamin $\mathrm{B}_{12}$ deficiency, renal failure or hypothyroidism were excluded from the study.The study was conducted after approval was obtained from the ethics committee of our hospital.

\section{Pulmonary Function Tests}

Pulmonary function tests (PFTs) were performed by 'VMAX'; 'Encore system (Germany)" device. During PFTs, post-bronchodilator force vital capacity in one second (FEV1), force vital capacity (FVC)and FEV1/FVC values were recorded based on GOLD criteria. For COPD staging, patients with FEV1 values $>80 \%$ were considered to have mild, FEV1: $80-50 \%$ were considered to have moderate, FEV1: $50-30 \%$ were considered to have severe and FEV $1<30 \%$ were considered to have very severe COPD.

\section{Arterial Blood Gas Analyses}

Analyses were performed by 2001 version of the "Instrumentation Laboratory-Synthesis 25" device. $\mathrm{pH}$, partial arterial oxygen pressure $\left(\mathrm{PaO}_{2}\right)$, partial arterial carbon dioxide pressure $\left(\mathrm{PaCO}_{2}\right)$ and arterial oxygen saturation $\left(\mathrm{SaO}_{2}\right)$ values were recorded.

\section{Electrophysiological Examination}

The examinations were performed using Medelec Synergy EMG device. In accordance with clinical definition of peripheral neuropathy (nerve conduction studies of at least 2 extremities); median nerve sensorial and motor conduction, ulnar nerve sensorial and motor conduction of the upper extremities and peronealnerve motor conduction, tibialnerve motor conduction and suralnerve sensorial conduction of the lower extremities, as well as all motor and sensorial nerve conduction studies were performed.A diagnosis of carpal tunnel syndrome (CTS) was made in the presence of a deceleration in median sensorial conduction velocity, prolongation of median motor nerve distal latency, a decrease in motor action potentials and the presence of at least $0.3 \mathrm{~ms}$ latency difference or latencies longer than $0.5 \mathrm{msec}$ when the ulnar-median nerve peak latency difference was compared to the other extremity. CTS was classified as mild, moderate and severe. Moreover; during each nerve conduction study, F wave (in at least one nerve for both an upper and a lower extremity) as one of the late latencies was investigated irrespective to the presence of findingssupporting polyneuropathy criteria. Most frequently, the right upper and lower extremities of the patients were studied. In patients who were found to have carpal tunnel syndrome, upper extremity nerve conductions were also evaluated.

\section{Statistical Analysis}

Statistical analysis was performed by SPSS 12 (Statistical Program for Social Sciences) software. Data were evaluated by using descriptive statistics (mean, standarddeviation). Independent sample test was used to compare the two groups andchi-square test was used to compare qualitative data. Data that were not normally distributed were compared between the two groups by Mann Whitney U test. A $p$ value $<$ 0.05 were considered significant in all statistical analyses of study data. 


\section{RESULTS}

Eleven $(24.4 \%)$ patients were women and 34 $(75.6 \%)$ were men and their mean age was $73.22 \pm$ 9.42 years. (Table 1) Never-smokers constituted $17.8 \%(\mathrm{n}=8)$ of the study population, while $71.1 \%$ (n $=32)$ were ex-smokers and $11.1 \%(n=5)$ were active smokers. Mean smoking history was $43.13 \pm 28.3$ pack-years. Body mass index (BMI) in neuropathy present group was $25.67 \pm 6.69 \mathrm{~kg} / \mathrm{m}^{2}$. Mean values of arterial blood gases (ABG) were as follows: $\mathrm{pH}$ : 7.41, $\mathrm{PaO}_{2}: 58.28 \mathrm{mmHg}, \mathrm{PaCO}_{2}: 41.27 \mathrm{mmHg}, \mathrm{SO}_{2}$ : $89.68 \%$. Mean PFT results were as follows: FEV1:46.71\% (1.19 1t), FVC:63.82\% (2.18 lt), FEV1/FVC:55.93. Of all patients, $4(8.9 \%)$ had electrophysiological changes while no change was noted in remaining 41 (91.1\%) patients (see Table 1). Patients were divided into two groups as those with or without neuropathy. Of the patients with neuropathy, one had motor neuropathy, 8 had sensorimotor neuropathy and 11 patients had sensorial neuropathy based on electrophysiological findings. In total, 7 patients had findings of carpal tunnel syndrome. Neuropathy was diagnosed in $44.4 \%(n=20)$ of the patients, while the remaining 55.6\% $(\mathrm{n}=25)$ did not have neuropathy (Table 1).

In total, 7 (63.64\%) women and 13 (38.24\%) men had neuropathy and their mean age was $75.30 \pm 9.07$ years. Of 25 patients without neuropathy, 21 (61.76\%) were men and $4(36.36 \%)$ were women and their mean age was $71.56 \pm 9.55$ years. Mean age and gender distribution were not significantly different between the two groups ( $p=0.204$ and $p=0.145$, respectively). In terms of $\mathrm{ABG}$ findings, mean $\mathrm{pH}$ of patients with neuropathy was $7.39 \pm 0.05$ (Table 2). There were significantly different between the two groups in term of $\mathrm{pO}_{2}(p=0.012), \mathrm{pCO}_{2}(p=0.003), \mathrm{SO}_{2}(p=0.001)$ and number of exacerbations per year $(p<0.001)$. Moreover, the percentage of smoking (pack-year) and mean modified Medical Research Council (mMRC) scores were also significantly different $(p=0.040$ and $p=0.001$, respectively). Mean age, smoking history, $\mathrm{pH}, \mathrm{FEV} 1$ (\%), FEV1 liters (lt), FVC (\%), FVC 1t, FEV1/FVC (\%), BMI and time since diagnosis of COPD (years) and co-morbidities (Coronary heart disease, Congestive heart disease, Alzheimer disease)
Table 1. Overall demographical characteristics

\begin{tabular}{|c|c|}
\hline Parameter & Data \\
\hline \multicolumn{2}{|l|}{ Gender } \\
\hline Women & $11(24.4 \%)$ \\
\hline Men & $34(75.6 \%)$ \\
\hline Age (mean) & $73.22 \pm 9.42$ \\
\hline \multicolumn{2}{|l|}{ Smoking } \\
\hline Never-smoker & $8(17.8 \%)$ \\
\hline Ex-smoker & $32(71.1 \%)$ \\
\hline Active-smoker & $5(11.1 \%)$ \\
\hline Smoking (packet-year) & $43.13 \pm 28.30$ \\
\hline \multicolumn{2}{|l|}{ Concomitant diseases } \\
\hline Present & $32(71.1 \%)$ \\
\hline Absent & $13(28.9 \%)$ \\
\hline pH & $7.41 \pm 0.044$ \\
\hline pO2, mmHg & $58.28 \pm 9.95$ \\
\hline pCO2, mmHg & $41.27 \pm 9.70$ \\
\hline $\mathrm{SO} 2, \%$ & $89.68 \pm 5.79$ \\
\hline FEV1, \% & $46.71 \pm 16.15$ \\
\hline FEV1, lt & $1.19 \pm 0.51$ \\
\hline FVC, $\%$ & $63.82 \pm 14.65$ \\
\hline FVC, lt & $2.18 \pm 0.70$ \\
\hline FEV1/FVC, \% & $55.932 \pm 11.37$ \\
\hline \multicolumn{2}{|c|}{ Electrophysiological Changes } \\
\hline Present & $4(8.9 \%)$ \\
\hline Absent & $41(91.1 \%)$ \\
\hline \multicolumn{2}{|l|}{ Neuropathy } \\
\hline Present & $20(44.4 \%)$ \\
\hline Absent & $25(55.6 \%)$ \\
\hline
\end{tabular}

Data are shown as mean \pm standart deviation or number (\%). $\mathrm{FVC}=$ force vital capacity, $\mathrm{FEV}_{1}=$ force vital capacity in one second, $\mathrm{pO}_{2}=$ partial oxygen pressure, $\mathrm{pCO}_{2}=$ partial carbon dioxide pressure, $\mathrm{SO}_{2}=$ oxygen saturation

were not significantly different between the two groups $(p>0.05)$ (Table 2). According to GOLD 2017 guideline, twenty-six (57.8\%) patients were GOLDStage C, $19(42.2 \%)$ were GOLD-Stage D. There were $5(19.2 \%)$ patients in GOLD-Stage C and 11 (57.9\%) patients in GOLD-Stage D, and this difference was statistically significant $(p=0.001)$.

Nerve conduction studies demonstrated significant differences in both median nerve distal latencies, right sural conduction velocity, right tibial nerve distal latency, both median nerve sensorial conduction velocity, right peroneal and tibial nerve motor conduction velocities between the two groups are shown in Table $3(p<0.05)$. 
Table 2. Comparison of the parameters between study groups

\begin{tabular}{|c|c|c|c|}
\hline & $\begin{array}{l}\text { Neuropathy present } \\
\qquad(\mathbf{n}=\mathbf{2 0})\end{array}$ & $\begin{array}{l}\text { Neuropathy absent } \\
\qquad(n=25)\end{array}$ & $p$ value \\
\hline Age (years) & $75.30 \pm 9.07$ & $71.56 \pm 9.55$ & 0.204 \\
\hline Smoking & $39.05 \pm 31.92$ & $46.40 \pm 25.22$ & 0.605 \\
\hline pH & $7.39 \pm 0.05$ & $7.41 \pm 0.03$ & 0.224 \\
\hline $\mathrm{pO}_{2}, \mathbf{m m H g}$ & $54.81 \pm 10.18$ & $61.75 \pm 7.76$ & 0.012 \\
\hline $\mathrm{pCO}_{2}, \mathrm{mmHg}$ & $46.67 \pm 11.16$ & $36.95 \pm 5.48$ & 0.003 \\
\hline SO2, \% & $86.67 \pm 5.86$ & $92.09 \pm 4.56$ & 0.001 \\
\hline FEV1 (\%) & $44.60 \pm 14.17$ & $48.40 \pm 17.68$ & 0.444 \\
\hline FEV1 (lt) & $1.15 \pm 0.46$ & $1.23 \pm 0.56$ & 0.775 \\
\hline FVC (\%) & $62.35 \pm 14.20$ & $64.70 \pm 14.60$ & 0.631 \\
\hline FVC (lt) & $2.00 \pm 0.62$ & $2.33 \pm 0.74$ & 0.132 \\
\hline BMI, $\mathrm{kg} / \mathrm{m}^{2}$ & $25.67 \pm 6.69$ & $25.39 \pm 5.75$ & 0.486 \\
\hline Time since COPD diagnosis (years) & $9.40 \pm 7.57$ & $7.32 \pm 6.27$ & 0.313 \\
\hline Number of exacerbations per year & $2.00 \pm 0.85$ & $1.04 \pm 1.31$ & $<0.001$ \\
\hline mMRC & & & 0.001 \\
\hline 1 & $0(0 \%)$ & $10(40 \%)$ & \\
\hline 2 & $10(50 \%)$ & $13(52 \%)$ & \\
\hline 3 & $9(45 \%)$ & $2(8 \%)$ & \\
\hline 4 & $1(5 \%)$ & $0(0 \%)$ & \\
\hline Smoking, (packet-year) & & & 0.040 \\
\hline Non-smoker & $6(30 \%)$ & $2(8 \%)$ & \\
\hline Ex-smoker & $13(65 \%)$ & $19(76 \%)$ & \\
\hline Active-smoker & $1(5 \%)$ & $4(16 \%)$ & \\
\hline
\end{tabular}

Data are shown as mean \pm standart deviation or number $(\%)$. BMI $=$ body mass index, COPD $=\mathrm{Chronic}$ Obstructive Pulmonary Disease, $\mathrm{FEV}_{1}=$ force vital capacity in one second, $\mathrm{FVC}=$ force vital capacity, $\mathrm{mMRC}=$ modified medical research council, $\mathrm{pO}_{2}=$ partial oxygen pressure, $\mathrm{pCO}_{2}=$ partial carbon dioxide pressure, $\mathrm{SO}_{2}=$ oxygen saturation

Table 3. Comparison of neurophysiological changes in electroneuromyography between groups

\begin{tabular}{lccc}
\hline & Neuropathy present & Neuropathy absent & $\boldsymbol{p}$ value \\
\hline RMNSL & $2.14 \pm 1.87$ & $2.89 \pm 0.94$ & 0.679 \\
LMNSL & $2.78 \pm 1.30$ & $2.92 \pm 0.71$ & 0.671 \\
RUNSL & $2.31 \pm 1.44$ & $2.71 \pm 0.33$ & 0.739 \\
RSNV & $19.36 \pm 18.13$ & $36.33 \pm 8.18$ & $<\mathbf{0 . 0 0 1}$ \\
RMNML & $3.84 \pm 0.69$ & $3.34 \pm 0.50$ & $\mathbf{0 . 0 1 2}$ \\
LMNML: & $3.49 \pm 0.59$ & $3.12 \pm 0.43$ & $\mathbf{0 . 0 3 2}$ \\
RUNML & $2.54 \pm 0.53$ & $2.47 \pm 0.57$ & 0.449 \\
RCPNL & $4.15 \pm 2.40$ & $4.49 \pm 1.19$ & 0.575 \\
PTNL & $4.79 \pm 0.99$ & $4.23 \pm 0.55$ & $\mathbf{0 . 0 4 7}$ \\
RMNSV & $21.60 \pm 18.80$ & $38.28 \pm 11.85$ & $\mathbf{0 . 0 0 1}$ \\
LMNSV & $31.42 \pm 14.43$ & $39.38 \pm 8.59$ & $\mathbf{0 . 0 0 1}$ \\
RUNMV & $27.66 \pm 16.68$ & $40.84 \pm 4.12$ & $<\mathbf{0 . 0 0 1}$ \\
RCPNV & $36.34 \pm 19.39$ & $46.17 \pm 11.51$ & $\mathbf{0 . 0 3 7}$ \\
RPTNV & $42.29 \pm 5.03$ & $45.93 \pm 5.48$ & $\mathbf{0 . 0 2 2}$ \\
\hline
\end{tabular}

Data are shown as mean \pm standart deviation. RMNSL $=$ Right median nerve sensory latency, LMNSL $=$ Left median nerve sensory latency, RUNSL = Right ulnar nerve sensory latency, RSNV = Right sural nerve velocity, RMNML $=$ Right median nerve motor latency, LMNML $=$ Left median nerve motor latency, RUNML $=$ Right ulnar nerve motor latency; RCPNL: Right common peroneal nerve latency, RPTNL = Right posterior tibial nerve latency, RMNSV = Right median nerve sensory velocity, LMNSV = Left median nerve sensory velocity, RUNMV = Right ulnar nerve motor velocity, RCPNV = Right common peroneal nerve velocity, RPTNV: Right posterior tibial nerve velocity 


\section{DISCUSSION}

The neuropathic patients are more hypoxic and hypercarbic than neuropathic and electrophysiologically normal COPD patients in our study. $\mathrm{pO}_{2}, \mathrm{pCO}_{2}, \mathrm{SO}_{2}$ and number of exacerbations per year were significantly different between the two groups. Moreover, mean modified Medical Research Council (mMRC) scores were also significantly different. The relation between chronic hypoxemia and peripheral neuropathy (PN) in COPD has been known for a long time [4, 5]. Hypoxia blocks energy metabolism of peripheral nerve tissue [6]. The severity of hypoxia may increase due to endothelial cell hyperplasia which results in luminal occlusion in capillary veins [4]. In rats with induced chronic hypoxemia, a reduction in nerve conduction velocity was observed as a result of axonal degeneration [7]. Stoebner et al. [8] observed microangiopathy caused by hypoxemia in peripheral nerves. While several studies reported a relation of hypoxemia and its severity with PNP, Jann et al. [9] found such a relation with the severity of COPD and hypercapnia.

Systemic inflammation is the key for linking COPD and most of its dependent comorbidities.In addition to inflammation, imbalance of proteinases and antiproteinases and the oxidative stress are important in the pathogenesis of COPD. In advanced COPD, the lung capacity reduces for gas exchange, producing hypoxemia and, later on, hypercapnia [10]. In the present study, significant associations were noted both with hypoxemia and hypercapnia. Also, frequent hospitalizations and therapies like systemic corticosteroids might contribute this situation [11].

Hypoxia and/or hypercapnia may occur or will get worse in COPD patients, especially during exacerbation. The inflammation also increases. Accordingly, we found a significant relationship between annual attack rate and frequency of neuropathy in our study. In addition mMRC dyspnea and frequency of neuropathy was directly correlated. The reason for this may be the probability of increased damage of neurons innervating diaphragm and other respiratory muscles by neuropathy.

The most important external source of oxidants is tobacco smoke and its constituents. Tobacco smoke damages the lungs, both by triggering inflammation and by direct effects of the inhaled particles and gases
$[12,13]$. Tobacco smoke causes protease-antiprotease imbalance by suppressing antiprotease activity. Resultant tissue damage may lead to local and systemic inflammation. In a previous study, Faden and Agrawal reported a correlation between smoking habits and sensorial nerve functions [14, 15]. Kayacan et al. [16] highlighted the concomitant relation between the brainstem auditory evoked potentials (BAER). According to that study, smoking affects the ponto-medullary brain region potentially by altering $\mathrm{PaCO}_{2}, \mathrm{HCO}_{3}$ and $\mathrm{pH}$ levels. On the contrary, Ulubay et al. [17] did not demonstrate such a relation in their study. The significant relation noted between smoking habits and neuropathy incidence in the present study can be explained by the high proportion of smokers in the study group.

In the present study peripheral neuropathy has occurred at an incidence of $44.4 \%$ in patients with COPD.The prevalence of PN among COPD patients showed wide variety in previous studies $(5 \%$ to $100 \%$ ) $[4,5,16,18,20-26]$. In line with the previous studies, the distribution and types of neuropathic parameters mostly indicated involvement of lower extremities and manifestation as sensorial NP [4, 20, 23, 24]. Neuropathy incidence varies depending on the clinical and electrophysiological criteria used to define the abnormalities.

\section{CONCLUSION}

In conclusion, chronic obstructive pulmonary disease is a systemic disorder that does not only involve the lungs, but also affects non-pulmonary organs through inflammation. This is important in terms of quality of life. Electroneurophysiological changes are rather common among patients who experience frequent hospitalizations, who are severely hypoxemic and/or hypercapnic. Nowadays, better identification of the comorbidities accompanying COPD may be beneficial for the patients in terms of early initiation of specific medical or supportive therapies.

\section{Conflict of interest}

The authors disclosed no conflict of interest during the preparation or publication of this manuscript. 


\section{Financing}

The authors disclosed that they did not receive any grant during conduction or writing of this study.

\section{REFERENCES}

[1] Global Initiative for Chronic Obstructive Lung Disease. Pocket guide to COPD diagnosis, management, and prevention. A Guide for Health Care Professionals 2017 edition. 2017.

[2] Kazi K, Mehta A, Mulla M. Electrophysiological evaluation of peripheral nerves in patients with chronic obstructive pulmonary disease. Int J Basic Appl Physiol 2012;1:83-7.

[3] Sönmezler A, Yoldaş TK, Ünsal İ, Çalık M, Karakaş E. [Who gets the diagnosis of polyneuropathy?] Journal of Harran University Medical Faculty 2012;9:65-7. [Article in Turkish]

[4] Pfeiffer G, Kunze K, Brüch M, Kutzner M, Ladurner G, Malin JP, et al. Polyneuropathy associated with chronic hypoxaemia: prevalence in patients with chronic obstructive pulmonary disease. J Neurol 1990;237:230-3.

[5] Paramelle B, Vila A, Pollak P, Muller P, Gavelle D, Reymond F, et al. Incidence of polyneuropathies in chronic obstructive bronchopneumopathies. Presse Med 1986;15:563-7.

[6] Tuck RR, Schmelzer JD, Low PA. Endoneurial blood flow and oxygen tension in the sciatic nerves of rats with experimental diabetic neuropahty. Brain 1984;107:935-50.

[7] Low PA, Schmelzer JD, Ward KK, Yao JK. Experimental chronic hypoxic neuropathy: relevance to diabetic neuropathy. Am J Physiol 1986;250:94-9.

[8] Stoebner P, Mezin P, Vila A, Grosse R, Kopp N, Paramelle B. Microangiopathy of endoneurial vessels in hypoxemic chronic obstructive pulmonary disease (COPD). A quantitative ultrastructural study. Acta Neuropathol (Berl) 1989;78:388-95.

[9] Jann S, Gatti A, Crespi S, Rolo J, Beretta S. Peripheral neuropathy in chronic respiratory insufficiency. J Peripher Nerv Syst 1998;3:69-74. [10] Barnes PJ, Celli BR. Systemic manifestations and comorbidities of COPD. Eur Respir J 2009;33:1165-85.

[11] Mantilla CB, Sieck GC. Neuromotor control in chronic obstructive pulmonary disease. J Appl Physiol 2013;114:1246-52.

[12] Wright JL, Lawson LM, Pare PD, Wiggs BJ, Kennedy S, Hogg JC. Morphology of peripheral airways in current smokers and ex-smokers.
Am Rev Respir Dis 1983;127:474-7.

[13] Hunninghake GW, Crystal RG. Cigarette smoking and lung destruction. Accumulation of neutrophils in the lungs of cigarette smokers. Am Rev Respir Dis 1983;128:833-8.

[14] Faden A, Mendoza E, Flynn F. Subclinic neuropathy associated with chronic obstructive pulmonary disease. Possible pathologic role of smoking. Arch Neurol 1981;38:639-42.

[15] Agrawal D, Vohra R, Gupta PP, Sood S. Subclinical peripheral neuropathy in stable middle-aged patients with chronic obstructive pulmonary disease. Singapore Med J 2007;48:887-94.

[16] Kayacan O, Beder S, Deda G, Karnak D. Neurophysiological changes in COPD patients with chronic respiratory insufficiency. Acta Neurol Belg 2001;101:160-5.

[17] Ulubay G, Ulasli SS, Bozbas SS, Ozdemirel T, Karatas M. Effects of peripheral neuropathy on exercise capacity and quality of life in patients with chronic obstructive pulmonary diseases. Arch Med Sci 2012;8:296-302.

[18] Gupta PP, Agarwal D. Chronic obstructive pulmonary disease and peripheral neuropaty. Lung India 2006;23:25-33.

[19] Gasnault J, Moore N, Arnaud F, Rondot P. Peripheral neuropathies during hypoxaemic chronic obstructive airways disease. Bull Eur Physiopathol Respir 1987;11:199-202.

[20] Moore N, Lerebours G, Senant J, Ozenne G, David P, Nouvet G. Peripheral neuropathy in chronic obstructive lung disease. Lancet 1985;11:1311.

[21] Shah S, Salvi, Kowale A. Peripheral nerves in chronic obstructive pulmonary disease: a review. Int J Adv Physiol Allied Sci 2016;3:78-87. [22] Ozge A, Atis S, Sevim S. Subclinical peripheral neuropathy associated with chronic obstructive pulmonary disease. Electromyogr Clin Neurophysiol 2001;41:185-91.

[23] Demir R, Özel L, Özdemir G, Kocatürk İ, Ulvi H. Neurophysiological changes in patients with chronic obstructive pulmonary diseases. Eur J Gen Med 2014;11:153-6.

[24] Jarratt JA, Morgan CN, Twomey JA, Abraham R, Sheaff PC, Pilling JB, et al. Neuropathy in chronic obstructive pulmonary disease: a multicentre electrophysiological and clinical study. Eur Respir J 1992; 5:517-24.

[25] Çağlar T, Aka MT, Tabakoğlu E, Utku U, Agun K. [Peripheral neuropathy in chronic obstructive pulmonary disease]. Balkan Med J 1994;11:185-91. [Article in Turkish]

[26] Oncel C, Baser S, Cam M, Akdağ B, Taspinar B, Evyapan F. Peripheral neuropathy in chronic obstructive pulmonary disease. COPD 2010;7:11-6. 